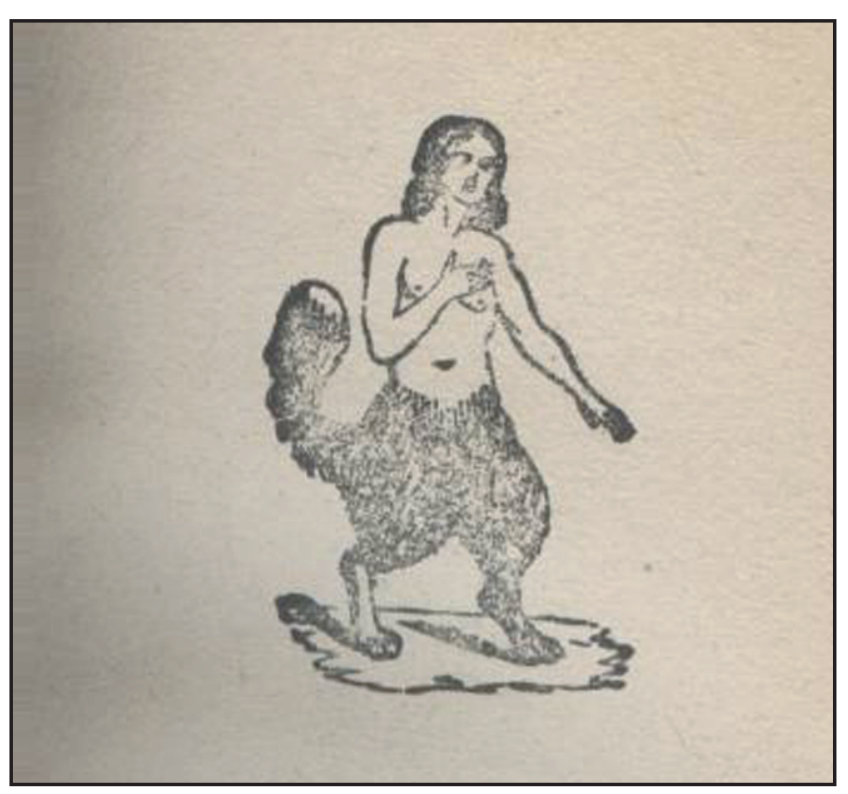

Figure 2 An otherwise healthy male adolescent with the legs, feet and tail of a dog according to Aristotle's Masterpiece

souls, and whether the devils can engender". There is a marvellous explanation for monstrous births in Aristotle's Masterpiece, which includes the phrase: "monsters are ascribed to depraved conceptions and are designated as being excursions of nature".

I am fortunate enough to own an early bound copy of Aristotle's Masterpiece. It has no authority or author and yet its influence spanned over and beyond two centuries.

\section{Future articles}

The next article in this series will be on the intriguing topic of chastity belts and birthing girdles.

\section{Acknowledgements}

The author would like to thank the following individuals for their help and advice: Dr Malcolm Colledge, University of Leeds, Leeds; Dr R Arnott, Director of the Centre for the History of Medicine, University of Birmingham Medical School, Birmingham and Dr G Williams, Curator of the British Museum, London, UK.

\section{Bibliography}

1 Karras, Ruth Mazo. Sexuality in Medieval Europe: Doing Unto Others. Abingdon, UK: Routledge, 2005.

2 Eccles, Audrey. Obstetrics and Gynaecology in Tudor and Stuart England. London, UK: Croom Helm Ltd, 1982.

3 Aristotle's Masterpiece (a manual of sex and pregnancy). Unknown author and publisher, circa 1684. (NB. Copies of this book can be found in antiquarian bookshops. Some of the later editions are reasonably priced but the earlier editions with little editing are much more fascinating.)

4 Lane, Joan. John Hall and His Patients. Stratford-upon-Avon, UK: The Shakespeare Birthplace Trust, 1996.

5 Lochrie, Karma; McCracken, Peggy; Schultz, James A (eds). Constructing Medieval Sexuality. Minneapolis, MN: University of Minnesota Press, 1997.

\section{About the author}

Lesley Smith is an Elizabethan historian currently studying for the degree of MPhil in the History of Medicine at Birmingham University Medical School. She is also Curator of Tutbury Castle in Staffordshire. Recently she has been given an honorary degree by the University of Derby for 'Services to History in the Community'. Lesley has appeared in over 30 television programmes, including Tony Robinson's The Worst Jobs in History, and is currently the resident historian in a live television programme that goes out across Europe. Lesley is also known as a public speaker, appearing at medical conferences and as an after-dinner speaker all over the UK.

\title{
NEWS ROUNDUP
}

\section{Ovarian cancer and HRT in the Million Women Study}

Ovarian cancer is the fourth most common cancer in women in the UK; however, there is limited information about the risk of ovarian cancer associated with the use of hormone replacement therapy (HRT). Some 948576 postmenopausal women from the UK Million Women Study who did not have previous cancer or bilateral oophorectomy were followed up for an average of 5.3 years for incident ovarian cancer and 6.9 years for death. Information on HRT use was obtained at recruitment and updated where possible. Relative risks for ovarian cancer were calculated, stratified by age and hysterectomy status, and adjusted by area of residence, socioeconomic group, time since menopause, parity, body mass index, alcohol consumption, and use of oral contraceptives. A total of 2273 incident ovarian cancers and 1591 deaths from the malignancy were recorded. Current users were significantly more likely to develop and die from ovarian cancer than never-users. For current users of HRT, incidence of ovarian cancer increased with increasing duration of use, but did not differ significantly by type of preparation used, its constituents, or mode of administration. Over 5 years, the standardised incidence rates for ovarian cancer in current and never-users of HRT were 2.6 and 2.2 per 1000 , respectively (i.e. one extra ovarian cancer in roughly 2500 users); death rates were 1.6 and 1.3 per 1000 , respectively (i.e. one extra ovarian cancer death in roughly 3300 users). In summary, women who use HRT are at an increased risk of both incident and fatal ovarian cancer.

Source: http://www.thelancet.com, online edition dated 19 April 2007
Abortion in long-term relationships More than one in ten women (12\%) aged 26-34 years have had an abortion whilst in a long-term relationship. The study conducted by Schering Health Care identified that $20 \%$ of these women were not using any contraception at the time they conceived and $27 \%$ conceived because they forgot to take their contraceptive pill. The findings suggest a need for better contraceptive education for women in long-term relationships and more information about emergency contraception

For more information contact Schering on 08450707612

\section{Fear and ignorance about abortion}

New research conducted by the University of Southampton, UK shows that because of myths about what having an abortion is like, women can be too frightened to seek abortion counselling or treatment earlier. Many do no know where to get impartial information about unintended pregnancy or abortion, which leads to delay in accessing an abortion. Some health professionals also seem to be confused about the facts of modern abortion techniques and don' always know where to refer women needing later abortions.

Ann Furedi, Chief Executive of bpas (British Pregnancy Advisory Service), said: 'Some women are putting off coming in to clinics as early as they need to, and going through weeks of terrible, unnecessary worry for simple want of the facts. School teachers and health professionals tend to skirt round the difficult issue of abortion so as not to cause offence, but this poses measurable risks to women's health. One-third of women in the UK will have an abortion before the age of 45 , so we all need to get real about offering this essential health information.

It's completely normal to need plenty of time to think about having an abortion. This is true at whatever stage a woman discovers her pregnancy. But some women don't have time on their side, so we need to remove as many of the other delaying factors as we can. A proper government pregnancy and abortion education campaign would be a big help."

\section{Source: http://www psychology soton.ac.uk/cshr}

\section{Looming crisis in abortion}

A warning was issued by the Royal College of Obstetricians and Gynaecologists (RCOG) about a looming "abortion crisis". An unprecedented number of doctors are opting out of terminating pregnancies, and the NHS struggles to cope. Richard Warren of the RCOG told a newspaper that more and more doctors now opt out. This has been blamed on shorter working hours of trainees and that doctors can choose which areas to work in. Ann Furedi, Chief Executive of bpas (British Pregnancy Advisory Service), commented: "Unless we can motivate doctors to train in abortion, we may face a situation in five years' time in which women's access to abortion is severely restricted". The ramification of this is potentially longer waiting lists, which would have the effect of more late terminations of pregnancy.

Source: The Times, 17 April 2007

Reported by Henrietta Hughes, MRCGP, DFFP

General Practitioner, London, UK 